\title{
PLANEJAMENTO E GESTÃO AMBIENTAL MUNICIPAL: UMA PROPOSTA METODOLÓGICA VISANDO A SUSTENTABLIDADE
}

\section{MUNICIPAL PLANNING AND MANAGEMENT: A METHODOLOGICAL PROPOSAL FOR THE SUSTAINABILITY}

\section{Clauciana Schmidt Bueno de Moraes ${ }^{1}$, Odaléia Telles Marcondes Machado Queiroz ${ }^{2}$, Frederico Fábio Mauad ${ }^{3}$}

${ }^{1}$ Pós-Doutorado em Ciências Ambientais/ CNPq, Doutora em Ciências da Engenharia Ambiental - EESC/ USP/ São Carlos-SP. Geógrafa/ UNESP. Administração/ UNIP. Professora-Orientadora de Pós-Graduação do CEGEA/ ESALQ/ USP e UNESP. email: clauciana@ig.com.br

${ }^{2}$ Doutora em Ciências da Engenharia Ambiental - CRHEA/ EESC/ USP/ São CarlosSP. Professora da Escola Superior de Agronomia Luiz de Queiroz - USP, Piracicaba, SP. e-mail: odaleiaq@terra.com.br

${ }^{3}$ Doutor em Planejamento de Sistemas Energéticos - UNICAMP/ Campinas - SP. Professor do Programa de Pós-Graduação em Ciências da Engenharia Ambiental e do Programa de Pós-Graduação em Hidráulica e Saneamento da EESC/ USP/ São Carlos - SP. e-mail: mauadffm@sc.usp.br

\section{RESUMO}

Este trabalho apresenta os resultados da aplicação da metodologia PLAMTUR - Planejamento Ambiental Municipal do Turismo, a qual objetiva contribuir na aplicação de técnicas para o planejamento de uma área. Além de, fundamentalmente, subsidiar estratégias de gestão ambiental, turística e aspectos relacionados, visando à ligação direta entre os objetivos teóricos e científicos e o proveito social. Este trabalho poderá, posteriormente, servir como modelo nos diversos aspectos relativos à implantação e gestão de uma determinada atividade econômica, por exemplo, o turismo, dentro dos parâmetros de desenvolvimento econômico, privilegiando a proteção ambiental e a responsabilidade social em empreendimentos e municípios.

Palavras-chave: Proteção ambiental. Desenvolvimento econômico. Responsabilidade social. Turismo. Município.

\footnotetext{
ABSTRACT

This paper presents the results of applying the methodology PLAMTUR - Municipal Environmental Planning for Tourism, which aims to contribute to the implementation of techniques for the planning of particular area. Furthermore, basically subsidize environmental management strategies, tourism and related, aiming at the direct link between the theoretical and scientific objectives and
} 
social advantage. This work can later serve as a model in many aspects of the deployment and management of a particular economic activity, this case exemplifies with tourism within the parameters of economic development, focusing on environmental protection and social responsibility in enterprises and municipalities.

Keywords: Environmental protection. Economic development. Social responsibility. Tourism. Municipalities.

\section{INTRODUÇÃO}

Os recursos naturais e/ou construídos aparecem como matéria-prima do turismo, sendo esses que sustentam e atraem o visitante para uma determinada área. Os recursos, porém, devem ser vistos como bens a serem não só explorados, mas principalmente conservados. Diante disso, ocorre o aumento na importância de estudos voltados a questão ambiental relacionadas ao turismo e, direta ou indiretamente, ligados às questões sociais, econômicas, dentre outras correlatas.

Alguns problemas ambientais que podem ser encontrados no município decorrentes, principalmente de administrações mal direcionadas, são concernentes aos aspectos como: consciência ecológica e ambiental, estrutura administrativa e recursos humanos, aspectos legais e conflitos institucionais, participação comunitária, processo de gestão, saneamento básico e ambiental, equipamentos urbanos, entorno e recursos naturais e no planejamento urbano e ambiental (PHILIPPI JUNIOR et al., 1999).

O enfoque deste trabalho visa a relação entre esses aspectos, exemplificando com a atividade turística, ou seja, às questões voltadas a mitigação e gestão de impactos/alterações negativas, mas principalmente a preocupação com a prevenção dos danos.

O planejamento e gestão, portanto, passam a ser não só uma forma de auxílio para administração e manejo de uma área, bem como da organização do espaço adequado as necessidades da população local e visitante, mas especialmente às características gerais da área.

Em relação às técnicas de planejamento e gestão que podem ser utilizadas no desenvolvimento de uma atividade econômica, neste caso o turismo, destacam-se algumas, como aquelas que são apresentadas na metodologia PLAMTUR - Planejamento Ambiental Municipal do Turismo, elaborada por Moraes (2006). Dentre algumas dessas técnicas apresentadas na metodologia destacam-se: o inventário, a avaliação prévia de impacto ambiental e o diagnóstico e análise preliminar, as quais fazem parte da primeira fase desta metodologia; e a etapa de zoneamento ambiental turístico, a qual compõe a segunda e última fase da metodologia.

$\mathrm{Na}$ etapa de inventário ocorre a divisão de duas outras etapas, o inventário municipal e aquele dos recursos paisagísticos e atrativos turísticos, e em cada uma dessas etapas ocorrem o levantamento e o reconhecimento de dados das características físico-ambientais, sócio-econômicas, político-administrativas, da infra-estrutura básica e turística e da demanda existente.

O inventário paisagístico de uma determinada área torna-se indispensável na contribuição para as estratégias de conservação e manejo de seus recursos, sendo este um instrumento necessário para a análise e avaliação dos impactos ambientais (MORAES e GUIMARÃES, 2001).

O valor real do potencial turístico de uma localidade não se mede somente pelo número de seus atrativos, mas também pela sua qualidade. Cada uma das fases se constituirá de estudos detalhados dos diversos e complexos componentes da oferta, que, após análise e avaliação sistemática, subsidiarão as demais etapas do plano de desenvolvimento turístico (RUSCHMANN, 2005).

$\mathrm{Na}$ avaliação prévia de impacto ambiental - APIA ocorre à identificação dos impactos positivos e negativos com ênfase para os aspectos sócio-econômicos, histórico-culturais e físicoambientais. 
O impacto ambiental é compreendido como toda alteração perceptível no meio, que comprometa o equilíbrio dos sistemas naturais ou antropizados, podendo decorrer das ações humanas (SANTOS, 2007). Pode-se definir ainda impacto ambiental como qualquer alteração das propriedades físicas, químicas e biológicas do meio ambiente causada por qualquer forma de matéria ou energia resultante das atividades humanas, que afetam: 1) a saúde, a segurança e o bemestar da população; 2) as atividades sociais e econômicas; 3) a biota; 4) as condições estéticas e sanitárias do meio ambiente; 5) a qualidade dos recursos ambientais (BRASIL, 1986).

$\mathrm{Na}$ etapa de diagnóstico e análise preliminar, ocorre inicialmente a síntese dos dados das etapas anteriores, com o diagnóstico das características do município e de cada recurso paisagístico e atrativo turístico, com a identificação dos pontos fracos e fortes, e posteriormente, a análise preliminar da situação atual e de todos os dados.

O zoneamento ambiental turístico é a quarta etapa do PLAMTUR que consiste na divisão do município em áreas geográficas que pretende a partir da análise dos dados obtidos nas etapas anteriores, identificar os principais aspectos físico-ambientais, sócio-econômicos, histórico-culturais e turísticos. O zoneamento é a compartimentação de uma região em porções territoriais, obtida pela avaliação dos atributos mais relevantes e de suas dinâmicas (SANTOS, 2007).

Assim, tais informações podem subsidiar o zoneamento, com aplicação de políticas, sendo este um importante instrumento para a definição da utilização dos espaços em uma unidade geográfica municipal ou em parte deste. Posteriormente, nesta mesma etapa ocorre a análise geral dos dados e a proposição de diretrizes como subsídios para o planejamento e gestão ambiental/ turística em um município e/ou empreendimento.

O turismo é um fenômeno dinâmico e complexo (BENI, 2007) e o ponto de equilíbrio na transição da economia será encontrado na planificação racional, que compatibilize os objetivos de crescimento da economia com a proteção e desenvolvimento dos recursos paisagísticos, em proveito de metas a um só tempo econômicas e ecológicas (AB' SABER, 1977), o que deve ser considerado na também na atividade turística e na busca pelo turismo sustentável.

O desenvolvimento deve ser voltado para a sustentabilidade a qual deve considerar alguns principais aspectos como: social, cultural, ecológico, ambiental e territorial (SACHS, 2002). O termo sustentabilidade foi bem explicado pela primeira vez dentro de um estudo realizado pela Comissão Mundial sobre Meio Ambiente das Nações Unidas, mais conhecido como Relatório Brundtland, que o define como sendo o desenvolvimento que satisfaz as necessidades atuais sem comprometer a habilidade das futuras gerações em satisfazer suas necessidades (WECD, 1987).

O planejamento ambiental representa então uma contribuição para a conservação da paisagem regional e a busca de novos caminhos para a exploração de cada recurso natural ou construído existente, assim como para o delineamento de planos diretores e para a elaboração de sistemas de leis de caráter protecionista, pertinentes à ocupação do solo e à organização do espaço (MORAES e GUIMARÃES, 2001).

Um estudo mais detalhado e completo pode proporcionar um direcionamento do planejamento e uma gestão ambiental e turística mais adequada e eficaz ao desenvolvimento da economia local, afim de uma maximização e/ou manutenção dos aspectos positivos e minimização e/ou prevenção dos aspectos negativos.

O trabalho apresenta como objetivos principais: 1) propor técnicas dentro de uma metodologia de planejamento e gestão que proporcionem à análise da viabilidade e aplicabilidade do desenvolvimento econômico na atividade turística correlacionada a proteção ambiental e a responsabilidade social; 2) elaborar a metodologia específica para o planejamento ambiental municipal do turismo - PLAMTUR, com as etapas de inventário, avaliação prévia de impacto ambiental, diagnóstico e análise preliminar e zoneamento ambiental turístico; e 3) analisar a viabilidade e a eficácia da elaboração e aplicação da metodologia PLAMTUR na ligação direta entre os objetivos teóricos e científicos e o proveito social, podendo servir de modelo para outros 
municípios e empreendimentos.

No desenvolvimento deste trabalho foi analisada a importância do planejamento e gestão, que interrelacionam questões como o desenvolvimento econômico, a inclusão e responsabilidade social e a proteção ambiental, bem como é apresentada a elaboração e a aplicação da metodologia PLAMTUR, como técnica para o subsídio de planos e projetos em municípios e empreendimentos, neste caso, exemplificada com a atividade turística.

\section{MATERIAL E MÉTODOS}

Como área de estudo deste trabalho foi escolhido o município de Charqueada, interior do Estado de São Paulo, devido às características locais com sua natureza privilegiada e sua situação atual de implantação da atividade turística como alternativa de desenvolvimento sócio-econômico local.

A metodologia PLAMTUR - Planejamento Ambiental Municipal do Turismo (MORAES, 2006) partiu do pressuposto da necessidade de elaboração de técnicas para subsidiar o planejamento e gestão ambiental em áreas que buscam a necessidade atual de se alcançar um desenvolvimento econômico, que ao mesmo tempo, promova a proteção ambiental e a responsabilidade e inclusão social. Esta metodologia tem o enfoque principal para as áreas turísticas ou que estão voltando suas atividades para o turismo, porém, a mesma pode ser utilizada posteriormente para fins correlatos às funções de planejamento e gestão ambiental, necessitando, porém de complementações e adaptações que se façam necessários as características, vocações, oportunidades de cada área para se atingir especificamente com objetivo proposto (Figura 1).

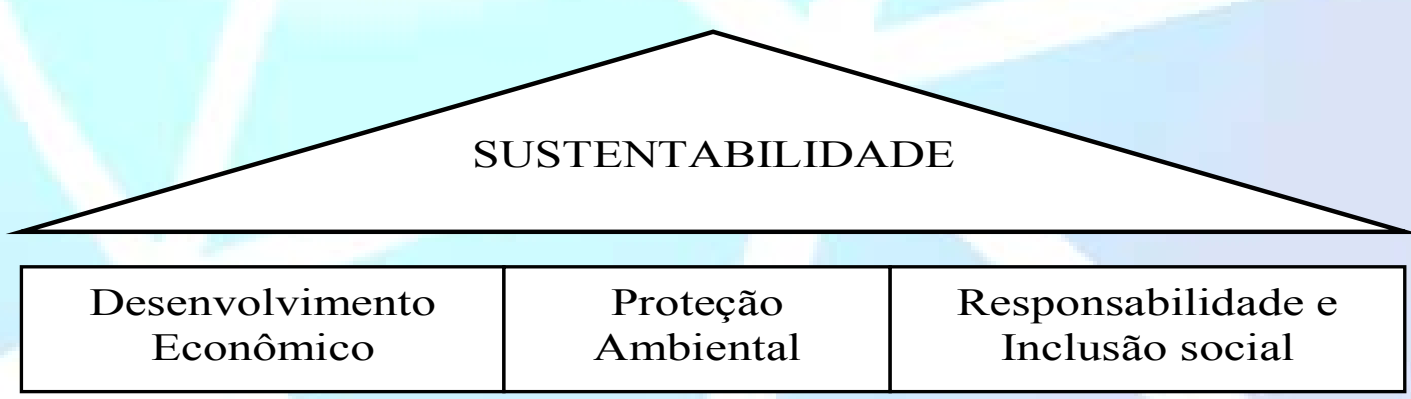

Figura 1. Inter-relação entre sociedade, economia e meio ambiente e a sustentabilidade. Fonte: Moraes (2006).

A metodologia PLAMTUR - Planejamento Ambiental Municipal do Turismo foi elaborado com a intenção de subsidiar essencialmente o direcionamento do desenvolvimento econômico atrelado à proteção ambiental e à inclusão social, em um município e/ou empreendimento, tendo como espaço de estudo às áreas onde ocorrem ou podem vir a ocorrer a atividade turística. $\mathrm{O}$ planejamento com enfoque a gestão sustentável tem a intenção de auxiliar planos, propostas e ações efetivamente positivas, ligados a esta atividade como também a outros aspectos.

Esta metodologia é dividida em duas fases que se completam entre si e que interrelacionadas subsidiam a proposição de diretrizes ambientais e turísticas e o delineamento para o planejamento e gestão geral de um empreendimento e/ou município nas questões que se referem ao turismo, ao meio ambiente, sociedade e aos demais aspectos relacionados.

Na metodologia PLAMTUR (Figura 2) pode-se notar a ordem do planejamento de cada fase e das etapas que as compõem, porém cada uma dessas é especificada a seguir: 
Primeira fase: esta fase é composta de três etapas: 1) inventário, 2) avaliação prévia de impacto ambiental - APIA, e 3) diagnóstico e análise preliminar.

Etapa 1 - Inventário: pode-se encontrar a divisão de duas grandes etapas, a) inventário municipal e b) inventário dos recursos paisagísticos e atrativos turísticos. Esta etapa foi baseada, porém readaptada de estudos já existentes como da Organização Mundial do Turismo - OMT (MORAES, 2006).

No caso do inventário municipal e dos recursos/atrativos turísticos ocorre a subdivisão em seis etapas: a) caracterização histórico-cultural, b) caracterização físico-ambiental, c) caracterização sócio-econômica, d) caracterização político-administrativa, e) caracterização da infra-estrutura básica e turística e f) caracterização da demanda.

Etapa 2 - Avaliação Prévia de Impacto Ambiental - APIA: ocorre a divisão em somente mais uma etapa: a) identificação dos impactos: onde ocorre a identificação dos impactos positivos e negativos no município em geral e em cada recurso paisagístico e atrativo turístico nos aspectos sócio-econômicos, histórico-culturais e físico-ambientais. Esta identificação é realizada por observação direta do pesquisador, indicando de modo geral os pontos que necessitam de uma maior atenção para a realização de estudos específicos de impacto ambiental.

Etapa 3 - Diagnóstico e análise preliminar: onde ocorre a divisão de outras duas sub-etapas: a) diagnóstico: há uma síntese dos dados do inventário e da avaliação prévia de impacto ambiental, onde ocorre o diagnóstico das características do município e de cada recurso paisagístico e atrativo, com a identificação dos pontos fracos e dos pontos fortes; b) análise preliminar da situação atual: análise geral dos dados do inventário, da APIA e do diagnóstico.

Segunda fase: esta fase é composta por uma única etapa a qual reúne, analisa todos os dados da primeira fase e finaliza a elaboração da metodologia, sendo esta:

Etapa 4 - Zoneamento ambiental turístico: nesta ocorre a divisão de duas sub-etapas: a) zoneamento ambiental-turístico: tendo aplicação de políticas, com a identificação das áreas nos aspectos físico-ambientais, sócio-econômicos, histórico-culturais e turísticos; b) proposição de diretrizes: onde ocorre posteriormente à elaboração do zoneamento a proposição de diretrizes como subsídios para o planejamento e gestão turística e ambiental (município e empreendimentos).

Com a proposição de diretrizes ocorre a finalização da elaboração e aplicação da metodologia PLAMTUR. Todavia, cabe lembrar que esta pode e deve ser sempre atualizada para que possa ocorrer um re-planejamento constante, sendo este necessário ao direcionamento eficaz dos diversos aspectos envolvidos a uma gestão sustentável.

O planejamento ou mesmo o re-planejamento, Portanto, deve ser fundamentalmente direcionado a gestão sustentável que respeite os aspectos econômicos, sociais, históricos, culturais e ambientais, bem como a perspectiva e as necessidades da população local e visitante, viabilizando a futura continuação dos diversos fatores correlacionados a esta atividade. 


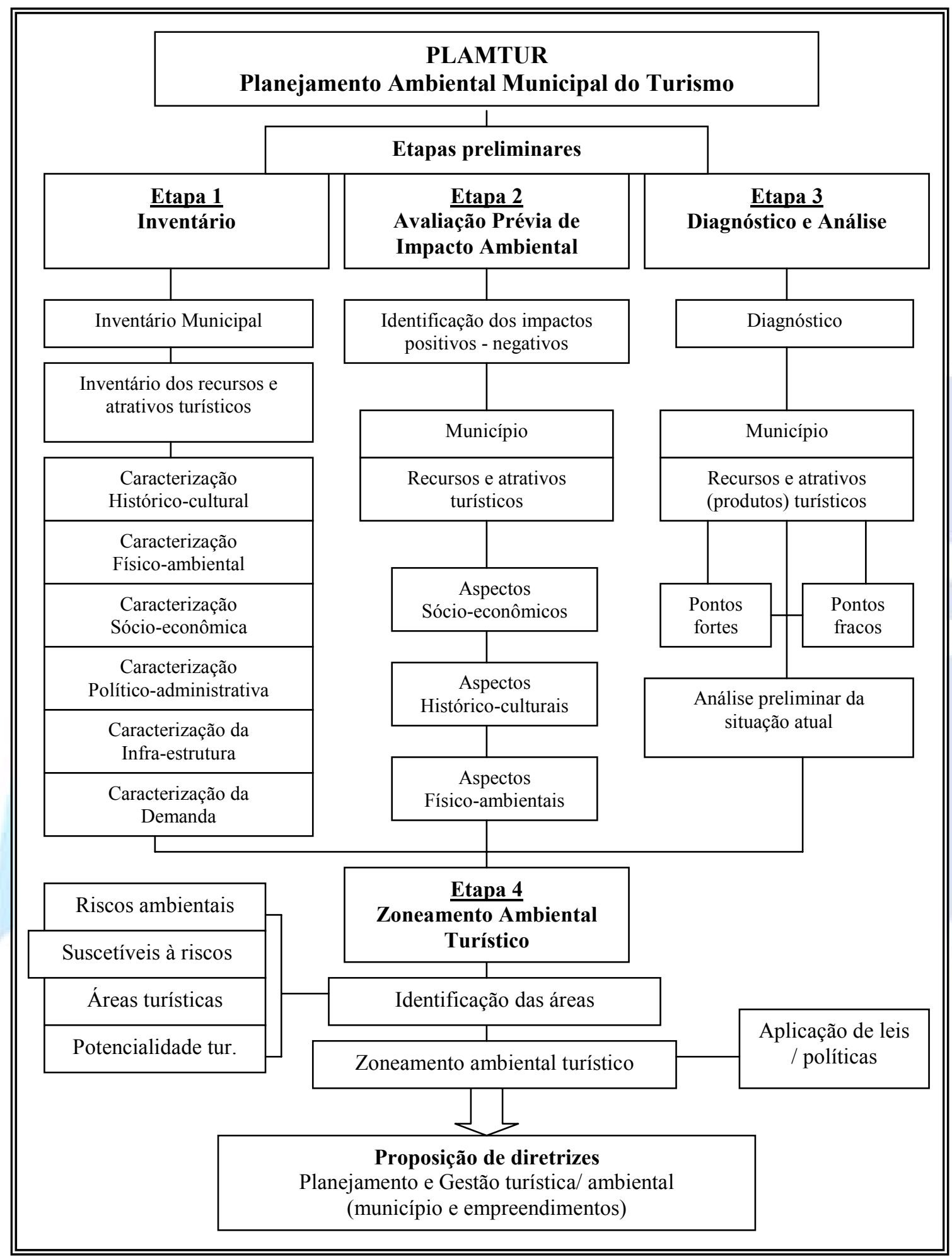

Figura 2. Esquema detalhado das etapas da metodologia PLAMTUR.

Fonte: Moraes (2006). 


\section{RESULTADOS E DISCUSSÃO}

\section{Aplicação da metodologia Plamtur}

A primeira das etapas da $1^{\text {a }}$ Fase do planejamento ambiental municipal do turismo PLAMTUR é a etapa do inventário, ou seja, da caracterização da área de estudo, no caso o município de Charqueada, em todos os seus aspectos, em especial, os de interesse para o planejamento e gestão ambiental voltadas para a sustentabilidade. Nesta etapa foram aplicados questionários junto aos responsáveis na administração do município e em cada recurso paisagístico e atrativo turístico.

Com o inventário, obteve-se a identificação de todos os aspectos do município de Charqueada e de cada atrativo existente na área. Os aspectos já citados anteriormente que foram levantados se dividem em: a) caracterização histórico-cultural; b) caracterização físico-ambiental; c) caracterização sócio-econômica; d) caracterização político-administrativa; e) caracterização da infra-estrutura; e f) caracterização da demanda.

Primeiramente ocorreu a identificação desses aspectos no município e posteriormente, em cada recurso paisagístico e atrativo turístico. Todavia, devido à grande extensão serão disponibilizados apenas os dados mais relevantes para o entendimento do trabalho, e os demais dados serão disponibilizados em forma de resultados neste trabalho, os quais podem ser verificados na íntegra no trabalho de Moraes (2006).

A área de pesquisa corresponde ao município de Charqueada que está localizado no interior do Estado de São Paulo, Brasil, com as coordenadas geográficas $47^{\circ} 47^{\prime}$ de longitude W de Gr. e $22^{\circ} 34^{\prime}$ de latitude S. Possui a área de $176 \mathrm{~km}^{2}$, confrontando com os municípios de Ipeúna, São Pedro, Itirapina e Piracicaba. O município está localizado a $195 \mathrm{~km}$ da Capital, sendo de fácil acesso às rodovias Anhangüera, Washington Luís e Bandeirantes, pelas rodovias SP-191 que liga Charqueada, Rio Claro e São Pedro e a rodovia SP-308 que liga Charqueada e Piracicaba.

No inventário dos recursos paisagísticos e atrativos turísticos existentes no município de Charqueada foram levantados os mesmos aspectos do inventário municipal. Todavia, a pesquisa em campo possibilitou a descrição precisa de cada recurso e atrativo, como também o levantamento dos dados em órgãos/ instituições ligadas à questão do meio ambiente e do turismo.

O município de Charqueada foi reconhecido como um município com potencial turístico pela EMBRATUR, e também no novo programa de regionalização turística, o que incentivou e continua incentivando atualmente o desenvolvimento e reestruturação de alguns recursos paisagísticos e atrativos turísticos para a melhoria desta atividade como oportunidade.

Ressalta-se que, mesmo os recursos/atrativos que não estão localizados dentro do limite do município de Charqueada são considerados neste trabalho, pois o município passa a ser o ponto estratégico de localização para estes, onde vários outros municípios também já utilizam a mesma estratégia para o planejamento e gestão de alguns dos pontos de visitação.

Os diversos recursos paisagísticos e atrativos turísticos existentes em Charqueada são classificados como ecoturismo e turismo ecológico, turismo rural e turismo histórico-cultural, os quais são apresentados na Figura 3. 


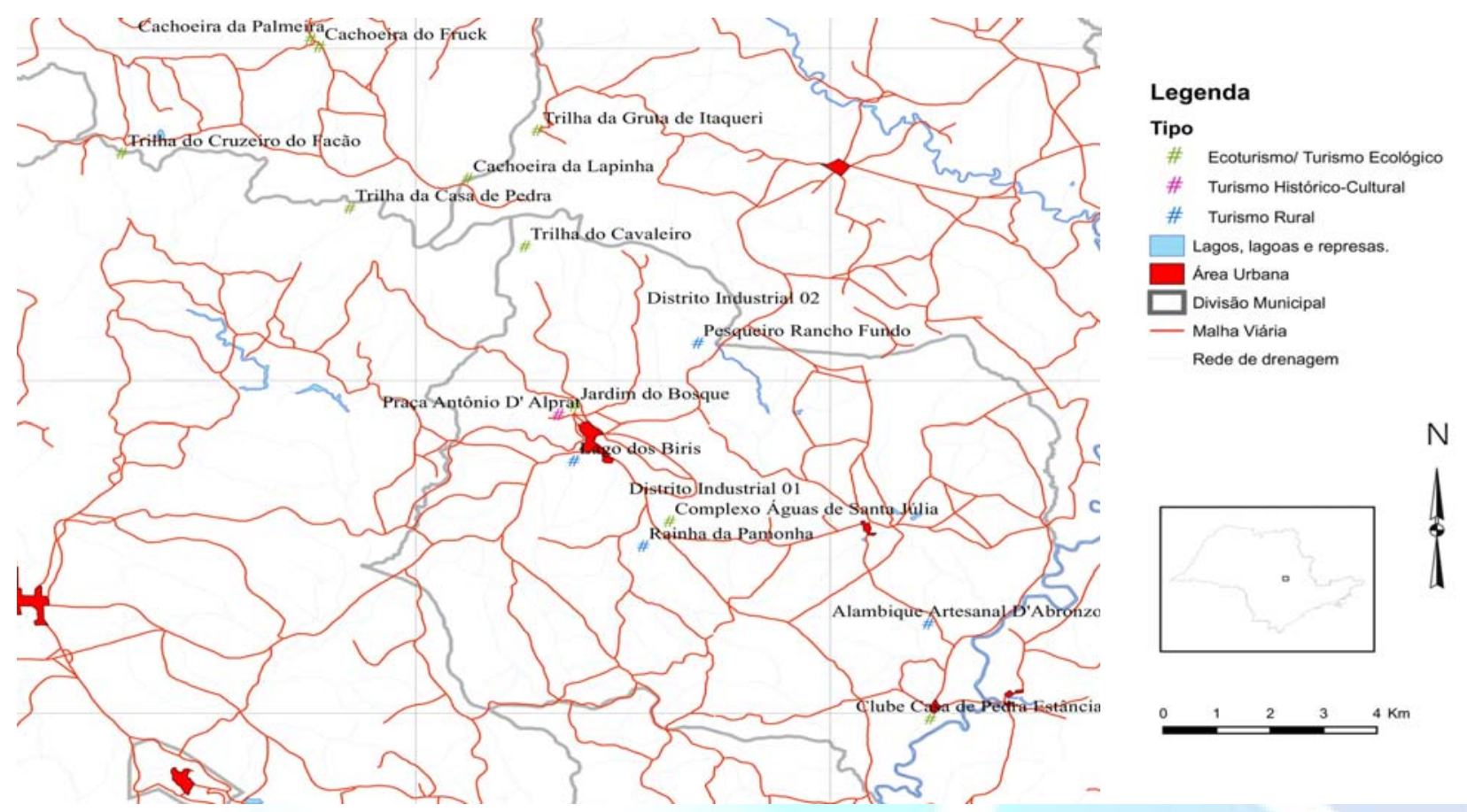

Figura 3. Mapa dos recursos paisagísticos e atrativos turísticos do município de Charqueada/ SP. Fonte: Moraes (2006).

\section{Avaliação Prévia de Impacto Ambiental}

A metodologia APIA tem como principal função anteceder o RAP - Relatório Ambiental Preliminar (BRASIL, 1986), pois nesta etapa obtém-se uma visão geral dos danos e/ou alterações que estão ocorrendo no meio ambiente avaliado, sendo esta baseada em especial nos princípios da observação direta (percepção) para a identificação dos impactos positivos e/ou negativos. Alguns indicadores de impactos foram baseados na metodologia da Organização Mundial do Turismo (OMT, 1994), porém a presente metodologia foi elaborada de acordo com a situação local, ou seja, do município que se encontra na fase de implantação e planejamento do turismo.

$\mathrm{Na}$ aplicação desta etapa 2 da metodologia, foi desenvolvida a técnica para a identificação dos possíveis impactos existentes, ou seja, a APIA, sendo esta um subsídio para levantamento de dados no município e em cada recurso e atrativo. Como já citado, porém sendo importante relembrar, no caso da APIA os impactos ambientais são as alterações positivas ou negativas no meio, seja decorrente da atividade humana ou da própria dinâmica da natureza em que os danos positivos ou negativos são reconhecidos pelo método de observação direta.

Cabe ressaltar, portanto, que os impactos positivos e negativos identificados na área do município e nos recursos e/ou atrativos não são especificamente decorrentes da atividade turística, mas que, no entanto, são impactos que interferem, direta ou indiretamente, nestes pontos turísticos. Os resultados da APIA são descritos em forma de resultados na etapa seguinte.

\section{Diagnóstico e Análise}

No diagnóstico e análise é demonstrada a síntese das etapas 1, inventário, etapa 2, avaliação prévia de impacto ambiental, e etapa 3, diagnóstico, incluindo os resultados de todos os dados obtidos anteriormente (Tabela 1), isto é, uma análise da situação em que se encontram os pontos estudados, direcionando posteriormente o zoneamento ambiental turístico e a proposição de diretrizes que subsidiarão o planejamento e gestão da área. 
Tabela 1 - Diagnóstico dos aspectos positivos e negativos do município de Charqueada, SP.

\begin{tabular}{|c|c|c|}
\hline $\begin{array}{c}\text { ASPECTOS/ } \\
\text { DIAGNÓSTICO }\end{array}$ & $\begin{array}{c}\text { PONTOS FORTES } \\
\text { (positivos) }\end{array}$ & $\begin{array}{c}\text { PONTOS FRACOS } \\
\text { (negativos) }\end{array}$ \\
\hline Histórico-culturais & $\begin{array}{l}\text { Calendário ativo de eventos e festas culturais e esportivos; } \\
\text { Aumento da preocupação com a conservação do } \\
\text { patrimônio histórico; } \\
\text { Existência de arquivo histórico municipal. }\end{array}$ & $\begin{array}{l}\text { Abandono de algumas áreas consideradas } \\
\text { patrimônios históricos, onde estas áreas } \\
\text { poderiam ser aproveitas também como } \\
\text { atrativos turísticos. }\end{array}$ \\
\hline Físico-Ambientais & $\begin{array}{l}\text { Localização do município com a proximidade das } \\
\text { principais rodovias de acesso do Estado e da capital, como } \\
\text { também em uma região com alto potencial turístico; } \\
\text { Aumento na valorização da paisagem; } \\
\text { Desenvolvimento de projetos ligados a área de } \\
\text { conservação ambiental como, por exemplo, o projeto } \\
\text { Charqueadinha de coleta seletiva do lixo e o projeto de } \\
\text { arborização municipal das áreas públicas; } \\
\text { Paisagem regional com potencial para o turismo; } \\
\text { Natureza diferenciada: cuestas basálticas, cachoeiras e } \\
\text { trilhas. } \\
\text { Nascente de água bicarbonata “Almeida Salles"; } \\
\text { Participação do município no SIGRH - Sistema de } \\
\text { Gerenciamento de Recursos Hídricos das Bacias do Rio } \\
\text { Piracicaba, Capivari e Jundiaí. }\end{array}$ & $\begin{array}{l}\text { Poluição do ar: queimada da cana-de-açúcar; } \\
\text { Pouca vegetação existente na área do } \\
\text { município, principalmente ao que se refere às } \\
\text { matas ciliares. } \\
\text { Poucos projetos de conscientização/ educação } \\
\text { ambiental (formal e não-formal) em } \\
\text { andamento e/ ou desenvolvidos. }\end{array}$ \\
\hline Sócio-Econômicos & $\begin{array}{l}\text { Criação de empregos: embora em números pequenos; } \\
\text { Maior incentivo financeiro nos setores de turismo e meio } \\
\text { ambiente; } \\
\text { Turismo em crescimento/ desenvolvimento como } \\
\text { oportunidade de emprego. }\end{array}$ & $\begin{array}{l}\text { Falta de mão-de-obra especializada; } \\
\text { Receita orçamentária municipal insuficiente } \\
\text { para investimentos nas áreas do turismo e } \\
\text { meio ambiente; } \\
\text { População migrante, geralmente composta por } \\
\text { trabalhadores que residem temporariamente no } \\
\text { município contratados pela Usina Cosan } \\
\text { (Piracicaba/ SP), trazendo muitas vezes gastos } \\
\text { para o município. } \\
\text { Alto índice de êxodo rural, comparando-se que } \\
\text { o setor que mais emprega no município é ainda } \\
\text { o agropecuário, e que é uma oportunidade para } \\
\text { o desenvolvimento do turismo rural. } \\
\text { Poucos projetos ligados à questão da } \\
\text { responsabilidade social. }\end{array}$ \\
\hline $\begin{array}{l}\text { Político- } \\
\text { Administrativos }\end{array}$ & $\begin{array}{l}\text { Região administrativa de Campinas: terceiro maior pólo } \\
\text { industrial do país; } \\
\text { Criação da divisão de turismo e meio ambiente na } \\
\text { administração municipal; } \\
\text { Criação do núcleo de educação ambiental; } \\
\text { Incentivo político para o desenvolvimento da atividade } \\
\text { turística no município. }\end{array}$ & $\begin{array}{l}\text { Ausência de um setor específico para o } \\
\text { planejamento urbano e também para a área de } \\
\text { meio ambiente; } \\
\text { Mão-de-obra especializada insuficiente na área } \\
\text { de turismo, meio ambiente e planejamento } \\
\text { urbano; } \\
\text { Ausência de Plano Diretor Municipal/ Agenda } \\
21 ; \\
\text { Ausência de Plano de Desenvolvimento } \\
\text { Municipal do Turismo. }\end{array}$ \\
\hline $\begin{array}{l}\text { Infra-estrutura } \\
\text { Básica/Turística }\end{array}$ & $\begin{array}{l}\text { Vias de acesso favoráveis ao tráfego do comércio e do } \\
\text { turismo; } \\
\text { Abastecimento de água, saneamento básico, coleta de lixo, } \\
\text { energia elétrica satisfatoriamente abrangente no } \\
\text { município; } \\
\text { Existência de infra-estrutura básica mínima na área da } \\
\text { saúde, com pronto socorro e centros de saúde em todos os } \\
\text { bairros mais distantes do centro do município; } \\
\text { Comunicação pública (telefones) abrangendo todas as } \\
\text { áreas públicas. } \\
\text { Inserção do município na região turística (proximidade) o } \\
\text { que facilita a interação entre municípios/ turistas. }\end{array}$ & $\begin{array}{l}\text { Pequeno número de sanitários nas vias } \\
\text { públicas e poucos sanitários para deficientes } \\
\text { físicos; } \\
\text { Pouca opção de horários e qualidade precária } \\
\text { no transporte no município e interurbano; } \\
\text { Ausência de placas indicativas (básicas/ } \\
\text { turísticas) e educativas; } \\
\text { Número pequeno de leitos para hospedagem; } \\
\text { Necessidade de maiores opções de } \\
\text { entretenimento; } \\
\text { Ausência do centro de informações turísticas; } \\
\text { Ausência de guias turísticos credenciados e } \\
\text { locais; } \\
\text { Ausência de mapa turístico atualizado. } \\
\end{array}$ \\
\hline
\end{tabular}

Fonte: OMT (1994) e Moraes (2006). 


\section{Zoneamento Ambiental Turístico}

A etapa 4 do PLAMTUR, o zoneamento ambiental turístico é a etapa final desta metodologia, seguida da proposição de diretrizes, as quais com o todo deste trabalho dão subsídios para o planejamento e gestão, deixando claro que não faz o planejamento, e sim subsidia o mesmo, pretendendo direcionar planos e propostas posteriores as vocações, intenções e necessidades para com a área.

Zoneamento ambiental turístico abrange toda área e subáreas de um município, seja esta urbana ou rural, como também todos os aspectos que compõem o meio ambiente como um todo, podendo ser aplicado e adaptado pontualmente a um empreendimento. Entende-se que cada área dentro de um município ou empreendimento tem suas características particulares e suas potencialidades e necessidades individuais, o que pode ou não algumas vezes ir de encontro com as características, potencialidades e/ou necessidades de outra localidade ou mesmo do contexto geral do município.

Torna-se necessário então, após o reconhecimento minucioso feito nas etapas anteriores desta pesquisa, inventário, avaliação prévia de impacto ambiental e diagnóstico e análise preliminar, realizarem o zoneamento ambiental turístico, objetivando auxiliar no planejamento e gestão adequados da área como um todo, facilitando assim posteriormente os estudos mais pontuais de cada empreendimento e subáreas dentro do município ou seu entorno.

O zoneamento ambiental turístico realizado aqui foi baseado em alguns tipos de zoneamento como o ecológico-econômico (ZEE) e ambiental, em programas e planos nacionais ligados a área de meio ambiente, economia, responsabilidade social, turismo e outras áreas correlatas, sendo algumas citadas mais especificamente a seguir. Destaca-se, porém, que todas as leis, decretos, normas, planos e programas utilizados como base para a elaboração do presente zoneamento foram considerados também nesta pesquisa.

O zoneamento ecológico-econômico estabelecido pela Lei no 4297 de 10 de julho de 2002 (BRASIL, 2002) estabelece medidas e padrões de proteção ambiental destinados a assegurar a qualidade ambiental, dos recursos hídricos e do solo e a conservação da biodiversidade garantindo o desenvolvimento sustentável e a melhoria das condições de vida da população. Tem por objetivo geral organizar de forma vinculada, as decisões dos agentes públicos e privados quanto a planos, programas, projetos e atividades que, direta ou indiretamente, utilizem recursos naturais, assegurando a plena manutenção do capital e dos serviços ambientais dos ecossistemas.

O ZEE na distribuição espacial das atividades econômicas considera a importância ecológica, as limitações e as fragilidades dos ecossistemas, estabelecendo vedações, restrições e alternativas de exploração do território e determinando, quando for o caso, inclusive a relocalização de atividades incompatíveis com suas diretrizes gerais.

O zoneamento ambiental estabelecido pela Lei no 6938 de 31 de agosto de 1981 (BRASIL, 1981) prevê preservação, reabilitação e recuperação da qualidade ambiental. Sua meta é o desenvolvimento socioeconômico condicionado à manutenção, em longo prazo, dos recursos naturais e melhoria das condições de vida do homem. Trabalha, essencialmente, com indicadores ambientais que destacam as potencialidades, vocações e fragilidades do meio natural. No caso do zoneamento turístico é algo que atualmente vem sendo pouco utilizado e discutido em termos de legislação, porém já aplicado em alguns trabalhos relacionados a este tema.

O Mapa de Zoneamento Ambiental Turístico (Figura 4) é resultado das informações levantadas em todo este trabalho, e também das informações contidas nos mapas dos aspectos físico-ambientais, sócio-econômicos, histórico-culturais e turísticos, que foram desenvolvidos neste trabalho como base para o mapa de zoneamento.

O principal critério utilizado como fundamento teórico-prático para elaboração do zoneamento ambiental turístico foi a utilização das questões da inter-relação entre a proteção ambiental, a responsabilidade social e o desenvolvimento econômico, neste caso com ênfase à 
atividade turística. $\mathrm{O}$ zoneamento propõe direcionar todo esse contexto subsidiando o planejamento e gestão ambiental, ressaltando que o ambiental envolve o todo e uma localidade, para o desenvolvimento da conscientização e de ações sustentáveis.

Este zoneamento tem o propósito de auxiliar no desenvolvimento sócio-econômico, interligado aos aspectos histórico-culturais e físico-ambientais e à melhoria da qualidade de vida do homem. Destaca neste caso, que serve para subsidiar planos e projetos e tomadas de decisões, considerando as principais características, potencialidades, vocações e fragilidades da área.

O zoneamento, portanto, auxiliará futuros projetos de zoneamento, como também para os demais planos e projetos, direcionando desta forma não só um conhecimento da área, mas também um sendo marco inicial para a valorização e aproveitamento das oportunidades, o que gera conseqüentemente a elaboração e ação de planos para o desenvolvimento econômico, responsabilidade social e proteção do meio ambiente.

\section{Proposição de diretrizes como subsídios para o planejamento e gestão ambiental.}

As diretrizes aqui propostas servem não só para o município de Charqueada/SP, o qual foi objeto de estudo deste trabalho, como também podem direcionar planos e projetos de outros municípios e/ou empreendimentos que tenham condições semelhantes, sejam em termos de características, vocações, fragilidades e até mesmo na intenção do desenvolvimento de planos e ações, para as questões ambientais, sociais, e também para o desenvolvimento econômico, neste caso com a exemplificação da atividade turística.

Essas diretrizes foram elaboradas a partir de todo o contexto do trabalho, desde o desenvolvimento do projeto, do estudo dos temas aqui tratados, até a elaboração geral da metodologia PLAMTUR desenvolvida nesta pesquisa.

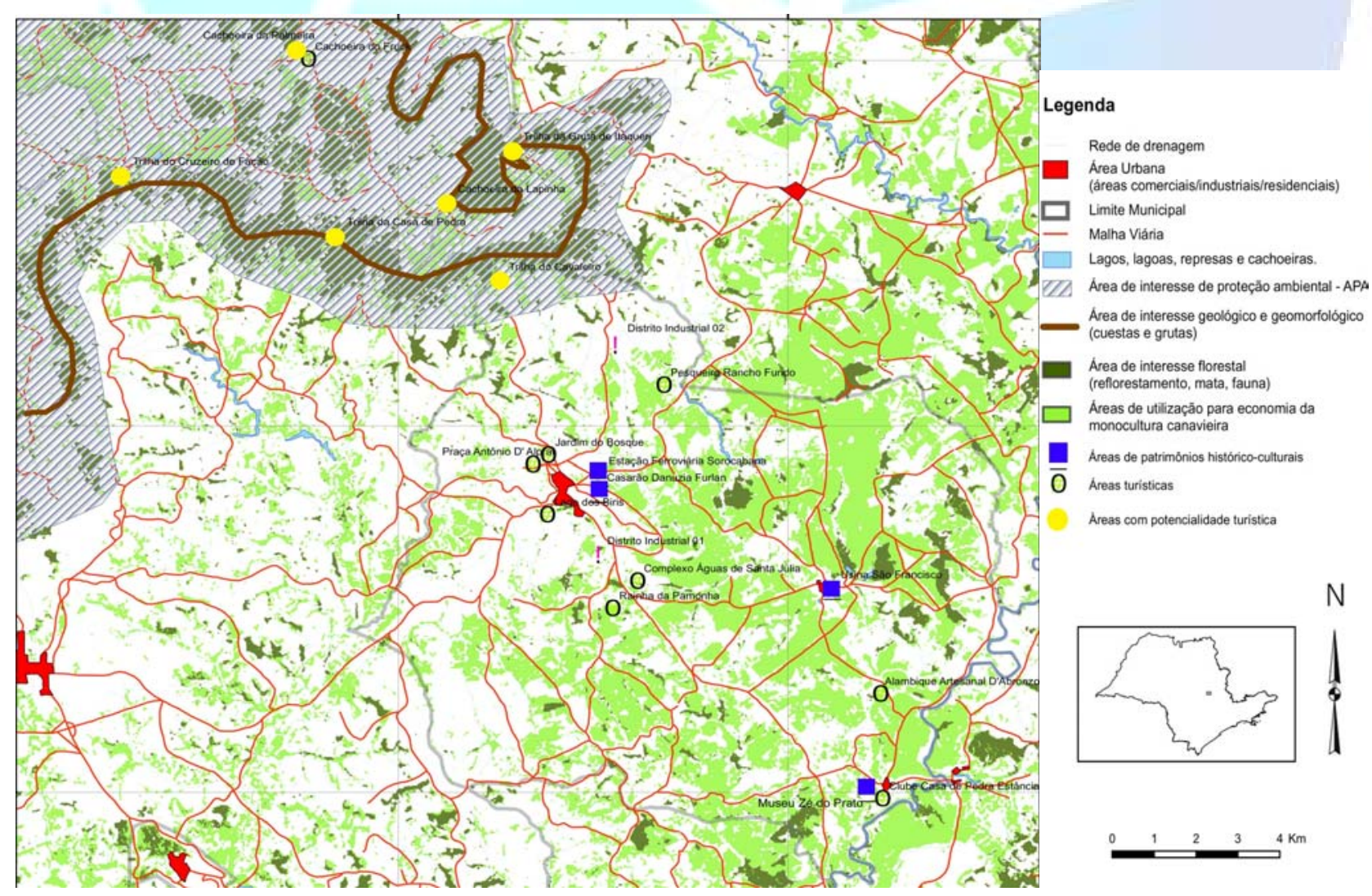

Figura 4. Mapa de Zoneamento Ambiental Turístico.

Fonte: Moraes (2006). 
As diretrizes são os resultados do contexto geral do trabalho como um todo, bem como pontos iniciais de conclusão, reflexão e discussão deste trabalho e também para futuros trabalhos, planos e projetos tanto para estudantes, pesquisadores, educadores, profissionais, poder público municipal e para a própria comunidade. Todavia, cabe lembrar que, pode haver algumas limitações para a aplicação das diretrizes para o planejamento e gestão ambiental como, por exemplo: a inclusão de aspectos relativos a opiniões das comunidades e equipes governamentais, perspectivas ou anseios da população, a ecodinâmica do meio ambiente e as características específicas de cada região.

As diretrizes citadas a seguir servem como subsídios para o planejamento e gestão ambiental, e em demais aspectos correlacionados da área em estudo, como também de exemplos para demais municípios e/ou empreendimentos. Essas diretrizes propostas são voltadas principalmente a questão turística, atreladas aos aspectos do desenvolvimento econômico, da responsabilidade social e da proteção ambiental, como questões imprescindíveis na busca e aplicação de planos, programas e ações sustentáveis.

Cabe ressaltar que a aplicação e/ou adaptação das diretrizes depende: a) de cada empreendimento em particular com ou sem o apoio do poder público; b) das condições de aplicação (como andamento, recursos financeiros, etc.) dos projetos/planos para da aplicação dessas diretrizes; c) do próprio governo municipal com apoio ou não dos demais poderes públicos estaduais, federais, além de instituições e organizações financiadoras de projetos relacionados a cada tema; e d) considerando os aspectos locais e também regionais da área em questão.

Cita-se, portanto, que de uma forma geral o município de Charqueada e os respectivos recursos paisagísticos e atrativos turísticos, necessitam de:

- Capacitação profissional na área de turismo e meio ambiente;

- Colocação de placas indicativas e educativas;

- Organizar visitas apenas com monitoramento;

- Melhorar a infra-estrutura básica, principalmente nas áreas de maior visitação;

- Implantar e/ou reestruturar a infra-estrutura turística adequada, mantendo as características culturais do local e conservando o recurso natural e construído;

- Providenciar infra-estrutura e/ou equipamentos de segurança, quando necessários;

- Direcionar setores específicos para questões na área ambiental e planejamento urbano dentro da administração pública;

- Desenvolver projetos que auxiliam o desenvolvimento do município e ou empreendimento na área social, ambiental e turística;

- Buscar incentivos financeiros junto a órgãos Federais e/ou Estaduais, para o desenvolvimento do turismo (economia), proteção do meio ambiente e de programas de inclusão social;

- Desenvolver projetos na área de marketing, conjuntamente com programas de gestão estratégica e mercadológica, como apoio ao planejamento e gestão dos empreendimentos e município em geral.

- Elaborar e implantar um plano de desenvolvimento e conservação ambiental e turística municipal, contínuo e sustentável.

- Estabelecer procedimentos que permitam o resgate das atividades de planejamento urbano, em bases ambientais, envolvendo a abordagem sistêmica.

- Elaborar projetos para o reconhecimento dos patrimônios histórico-culturais, junto aos órgãos competentes, como o IPHAN - Instituto do Patrimônio Histórico e Artístico Nacional.

- Encaminhar o desenvolvimento de mecanismos participativos na formulação e implantação de planos, programas e projetos ambientais, sociais e econômicos nos âmbitos municipais e estaduais.

- Estruturar o município para a adoção de instrumentos de gestão ambiental de caráter preventivo, em especial o zoneamento ambiental, a avaliação de impacto ambiental e análise de risco. 
- Incluir a educação ambiental como tema transversal a ser aplicada na implantação de políticas públicas e ambientais nos diversos níveis de governo, com o desenvolvimento de programas e ações ligados direta e/ou indiretamente a educação ambiental formal e não-formal;

- Estruturar o sistema municipal de meio ambiente - Sismuma, incluindo conselhos colegiados, com competências para a formulação e aplicação da política ambiental e urbanística.

- Fortalecer a capacitação de agentes municipais para o desenvolvimento e aplicação dos instrumentos preventivos, e de controle e mitigação de impactos ambientais.

- Sugerir a implantação de instrumentos de gestão ambiental (como por exemplo, os sistemas de gestão - ISO e sistemas de gestão integrados) em empreendimentos industriais e turísticos.

- Adotar o gerenciamento ambiental específico para projetos e obras municipais de grande porte (casos necessários - EIA-RIMA).

- Adotar a aplicação de Relatórios de Impacto de Vizinhança para a prevenção e controle de impactos ambientais decorrentes da implantação de projetos de médio porte, estruturados a partir da análise de compatibilidade com o planejamento e com o zoneamento ambiental e urbano e turístico e demais atividades, e considerando-se a capacidade de suporte da infra-estrutura viária, de saneamento e outras (elaboração do zoneamento de acordo com a legislação).

- Elaborar e difundir um manual de diretrizes (geral) para o planejamento e a gestão ambiental, que servirá como base para os planos, projetos, programas e ações locais/ pontuais em cada área a ser aplicada. Este manual de diretrizes deve conter alguns itens principais, os quais são sugeridos a seguir.

a) Agentes envolvidos: comunidade, população visitante, poder público, instituições e profissionais.

b) Prazos: (curto/médio/longo) dependem do andamento dos projetos e possíveis imprevistos e deve ser considerado a ecodinâmica do meio ambiente e a aplicação da abordagem sistêmica.

c) Tipo de diretrizes: preventivas, corretivas/adaptativas, inclusivas.

d) Fundamento geral (pontos a considerar): propor em todo e qualquer contexto planos e medidas que devam abranger e interrelacionar questões como: responsabilidade social, economia, (no caso utilizando a atividade turística e demais atividades) e a proteção ambiental, em busca de sustentabilidade.

As diretrizes propostas foram chamadas de diretrizes como subsídios para o planejamento e gestão ambiental, pois, abrangem o meio como um todo e não somente os aspectos físicoambientais, mas também os aspectos histórico-culturais, sócio-econômicos, político-administrativos e da infra-estrutura básica e turística, e devem seguir preferencialmente cada necessidade primordial para sua aplicação, e posteriormente para implantação de cada plano e projeto.

Cabe lembrar, entretanto, que essas diretrizes devem ser revistas considerando as alterações que podem ocorrer em cada etapa do planejamento/ gestão e a dinâmica do meio ambiente, sendo quando se fizer necessário, atualizadas e complementadas com a situação presente da área.

A proposição de diretrizes como subsídios para o planejamento e gestão ambiental e aspectos correlatos que corresponde a fase final da metodologia, é um direcionamento para a área em estudo, como também serve de exemplo para outros municípios e empreendimentos, considerando estas como sugestões importantes no que se refere a busca e manutenção da sustentabilidade.

Esse trabalho demonstrou a importância de se considerar questões de valorização do meio, aproveitamento das oportunidades de crescimento econômico, e melhoria da qualidade de vida, bem como do aproveitamento das oportunidades e vocações locais, e pretende servir como base para outros trabalhos específicos e imprescindíveis para o município/empreendimento em estudo, mas também como base para outros estudos em outras áreas, em todas as questões aqui trabalhadas, mas essencialmente na melhoria da qualidade do meio ambiente e na qualidade de vida do próprio homem. 


\section{CONSIDERAÇÕES FINAIS}

A metodologia aqui proposta servirá como subsídio para o planejamento, implantação e gestão da atividade econômica com respeito às características da área, ao meio ambiente a população local e visitante. Portanto, pode-se concluir que a metodologia é viável de aplicação (podendo haver readaptações), para municípios e empreendimentos que possuam características, fragilidades, vocações, potencialidades semelhantes à área aplicada neste trabalho, sendo esta um subsídio importante para o planejamento e gestão.

Com relação à atividade turística, conclui-se que esta serve como oportunidade viável, porém interligada as demais atividades econômicas de uma área, para o desenvolvimento/crescimento da economia, para a responsabilidade social e para a valorização e proteção dos aspectos ambientais e histórico-culturais.

Com relação ao trabalho geral conclui-se que para a eficácia e sucesso da metodologia, como de outros instrumentos para o planejamento e gestão ambiental, torna-se imprescindível a inter-relação e aplicação das questões como a busca de um desenvolvimento econômico interrelacionado à responsabilidade social e a proteção ambiental, considerando estas questões básicas e necessárias para sustentar a qualidade do meio ambiente e a qualidade de vida.

Dentre alguns projetos e/ou planos que podem servir de base e auxílio esta metodologia, sugere-se para o município estudado a implantação de programas e projetos, como: Programa de Regionalização do Turismo (Plano de Desenvolvimento Municipal do Turismo); Plano Diretor (Zoneamento Municipal); Programas de Educação Ambiental Formal e Não-formal; Programas de Responsabilidade e Inclusão Socioambiental; Programas de Proteção Ambiental; Programas de Proteção/Valorização do Patrimônio Histórico-Cultural; Programas de Valorização das APAs Áreas de Proteção Ambiental; Programas de Desenvolvimento Econômico; Programas de Proteção às Áreas Especiais e de Interesse Turístico.

Enfim, pode-se chegar a diversas conclusões que são apresentadas em cada contexto deste trabalho e da metodologia aqui elaborada, mas a conclusão neste caso é que pretende iniciar reflexões, discussões, criação de planos e ações, mas essencialmente servir como subsídio para o planejamento e gestão ambiental, na aplicação de uma gestão contínua e efetiva de planos e ações viáveis na ligação direta entre os objetivos teóricos e científicos de uma pesquisa e sua aplicação para o proveito social.

\section{AGRADECIMENTOS}

Ao CNPq - Conselho Nacional de Desenvolvimento Científico e Tecnológico pelo apoio. Ao PPG-SEA do Centro de Recursos Hídricos e Ecologia Aplicada da EESC/ USP.

\section{REFERÊNCIAS}

AB' SABER, A.N. Potencialidades paisagísticas brasileiras. Recursos Naturais, Meio Ambiente e Poluição. Rio de Janeiro, IBGE, p. 19-38, 1977.

BENI, M. Análise estrutural do turismo. 12 ${ }^{\text {a }}$ (ed.) São Paulo: SENAC, 2007.

BRASIL. Ministério do Meio Ambiente. Conselho Nacional do Meio Ambiente. Resolução CONAMA n ${ }^{\circ 01}$, de 23 de janeiro de 1986. Diário Oficial da União. Brasil, 1986. 
BRASIL. Decreto-Lei no 4297 de 10 de Julho de 2002. Diário Oficial da União. Brasil, 2002.

BRASIL. Lei no 6938 de 31 de Agosto de 1981. Diário Oficial da União. Brasil, 1981.

MORAES, C.S.B. Planejamento e Gestão Ambiental: uma Proposta Metodológica. 2006. 277 f. Tese (Doutorado em Ciências da Engenharia Ambiental). Escola de Engenharia de São Carlos, Universidade de São Paulo, São Carlos, 2006.

MORAES, C.S.B.; GUIMARÃES, S.T.L. Subsídios para a Implantação do Turismo Ambiental no Município de Charqueada/ SP. Revista Holos Environment. Rio Claro: CEA/ UNESP. v.1, n.1, 2001.

OMT - Organização Mundial do Turismo. Planejamento para o Desenvolvimento de Turismo Sustentável em Nível Municipal. Canadá: OMT. Publicação de Turismo e Ambiente, 1994.

PHILIPPI JR, A. ; MAGLIO, I.C. ; COIMBRA, J.Á. A.; FRANCO, R. M. Municípios e Meio Ambiente - Perspectivas para a Municipalização da Gestão Ambiental no Brasil. São Paulo: Associação Nacional dos Municípios e Meio Ambiente - ANAMMA, 1999. v. 1. 201 p.

RUSChMANN, D. V. M. Turismo e Planejamento Sustentável: A Proteção do Meio Ambiente. Campinas: Papirus. 12a (ed.) 2005.

SANTOS, R.F. Planejamento Ambiental: Teoria e Prática. São Paulo: Editora Oficina de Textos, 2007.

SACHS, I. Caminhos para o Desenvolvimento Sustentável. Rio de Janeiro: Editora Garamnond. $4^{\text {a }}$ (ed.), 2002.

WCED - World Commission on Environment and Development. Our Common Future. Oxford, U.K.: Oxford University Press, 1987. 383 p. 